\title{
The role of cAMP signalling in the symbiosis between Epichloë festucae and Lolium perenne
}

\author{
C.R. VOISEY ${ }^{*}$, M.J. CHRISTENSEN ${ }^{1}$, R.D. JOHNSON ${ }^{1}$, L.J. JOHNSON ${ }^{1}$, A.K. KHAN ${ }^{2}$, Z.A. PARK ${ }^{1}$, M. RAMAKRISHNA ${ }^{1}$, \\ M. CAO ${ }^{1}$, J.P. KOOLAARD ${ }^{1}$, A. KOULMAN ${ }^{1}$, S. BORCHERT ${ }^{1}$, C.N. GABORIT ${ }^{1}$, J.M. PRATT ${ }^{1}$, S. RASMUSSEN ${ }^{1}$ and G.T. BRYAN ${ }^{1}$ \\ ${ }^{1}$ AgResearch Grasslands, Tennent Drive, Private Bag 11-008, Palmerston North 4442, New Zealand. \\ ${ }^{2}$ AgResearch, Invermay Agricultural Centre, Puddle Alley, Private Bag 50034, Mosgiel, New Zealand \\ * christine.voisey@agresearch.co.nz
}

\begin{abstract}
In fungal pathogenesis the cAMP signalling cascade is usually essential for virulence. Deletion of the adenylate cyclase gene, the enzyme that synthesises cAMP, often results in an attenuated or avirulent phenotype. Our aim was to identify the signalling mechanisms regulating colonisation of perennial ryegrass (Lolium perenne) by the fungal symbiont Epichloe festucae Fl1. We have identified genes from several signalling networks, and here report on the outcomes of targeted disruption of the E. festucae F11 adenylate cyclase gene ( $a c y A)$. A dual genome (endophyte/ ryegrass) Affymetrix GeneChip ${ }^{\circledR}$ has been synthesised and we are undertaking large scale transcript profiling of the L. perenne/ E. festucae $\triangle a c y A$ symbiotum to identify target genes regulated by the endophyte cAMP signalling network.

Keywords: cAMP, adenylate cyclase, acyA, Neotyphodium lolii, Epichloë festucae, symbiosis, Affymetrix GeneChip ${ }^{\mathbb{R}}$
\end{abstract}

\section{Introduction}

Signalling pathways facilitate transduction of stimuli from the exterior of cells to the interior, enabling the organism to respond to environmental and biological stimuli by altering growth, differentiation or the production of secondary metabolites. Adenosine 3' 5 ' - cyclic AMP (cAMP) is an integral component of signalling cascades in most organisms. Levels of cAMP are modulated by the activity of two enzymes, adenylate cyclase and phosphodiesterase, responsible for the synthesis and degradation of cAMP respectively. The most well characterised target of cAMP is cAMP-dependent protein kinase, which mediates many of the physiological effects of cAMP in fungi (D'Souza \& Heitman 2001) by phosphorylating target proteins such as protein kinases, ion channels and transcription factors. In eukaryotes, cycles of phosphorylation and dephosphorylation are a major mechanism by which cellular pathways are activated or deactivated. In fungi, the cAMP signalling pathway has been shown to play a role in

Figure 1 Map of acyA disruption vector pCRVacyhph. The acy $A$ disruption plasmid contains the hygromycin resistance gene $(h p h)$ flanked by $3 \mathrm{~kb}$ border sequences from acyA. The hph gene is controlled by the gpdA promoter and TrpC terminator from Aspergillus nidulans.

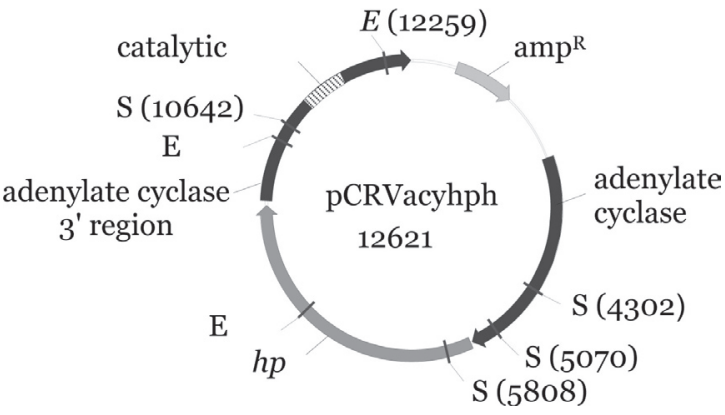

several critical processes in pathogenesis, and deletion of the adenylate cyclase gene results in an attenuated (Klimpel et al. 2002) or avirulent phenotype (Brakhage \& Liebmann 2005; Choi \& Dean 1997; D’Souza \& Heitman 2001).

The molecular mechanisms by which fungal endophytes, Epichloë and Neotyphodium colonise grasses are still largely unknown. In these symbioses, endophytic hyphae adhere to plant cell walls in the intercellular spaces of the host, hyphal growth is coordinated with leaf growth (Tan et al. 2001), and the production by endophytes of secondary metabolites within the host is regulated by both environmental and plant factors (Rowan 1993; Spiering et al. 2005). We have identified genes from several signalling networks, and here report on the disruption of adenylate cyclase, and the impacts of depleted cAMP on the symbiosis between $E$. festucae Fl1 and L. perenne.

\section{Material and Methods}

\section{Fungi, plants and growing conditions}

Fungi were grown in culture on potato dextrose agar (PDA) at $22^{\circ} \mathrm{C}$. L. perenne cv. Nui plants infected with wild type (w.t.) or hygromycin-resistant E. festucae Fl1 transformants were maintained in glasshouse conditions as described (Voisey et al. 2007). For production of conidia E. festucae isolates were transferred to water agar and incubated at $22^{\circ} \mathrm{C}$ for 28 days.

\section{Cloning and disruption of the adenylate cyclase gene}

A PCR fragment of the $N$. lolii Lp19 adenylate cyclase gene $($ acyA) was cloned from DNA amplified using degenerate primers with homology to the adenylation domain of nonribosomal peptide synthetases (Johnson et al. 2007b). The 300bp sequence was labelled with digoxigenin (DIG, Roche) and used as a probe to identify homologous clones from a lambda library (Fleetwood et al. 2007) of N. lolii Lp19 genomic DNA. A single homologous clone was recovered and the DNA insert sequenced. BLASTX analysis indicated that the entire 6057bp insert comprised most of the adenylate cyclase gene barring the first $750 \mathrm{bp}$ of the open reading frame (ORF). Alignment of the gene with the adenylate cyclase genes of other fungi revealed a high degree of sequence conservation with adenylate cyclases from Metarhizium anisopliae and Gibberella zeae. Analysis of the conceptual adenylate cyclase protein confirmed that key motifs consistent with fungal Class III adenylate cyclase genes were present, including the adenylate cyclase catalytic core, the protein phosphatase $2 \mathrm{C}$ box 1 and box 2 residues, and the Rasassociated domain.

To disrupt $a c y A$, the hygromycin resistance gene $(h p h)$ was inserted upstream of the putative catalytic domain of the adenylate cyclase gene. A gene replacement vector, pCRVacyhph (Fig. 1), was constructed using the Gateway multi-site system (Invitrogen). The $h p h$ cassette from pAN7 (Punt et al. 1987) was flanked either side with $3 \mathrm{~kb}$ of DNA with homology to $a c y A$ using the procedure described in Fleetwood et al. (2007) . Gene disruption experiments were performed in E. festucae strain Fl1 
(originally an isolate from Festuca longifolia). Homologous recombinants of $E$. festucae Fll were obtained by PEG-mediated transformation of protoplasts. Protoplasts were prepared using the method of Young et al. (1998), except that $10 \mathrm{mg} / \mathrm{ml}$ of Glucanex (Interspex) was used to digest the cell walls for 3 hours at $30^{\circ} \mathrm{C}$ with shaking (100 rpm). E. festucae strain F11 was transformed using $5 \mu \mathrm{g}$ of each plasmid by the method of Vollmer \& Yanofsky (1986) with modifications (Itoh et al. 1994). Transgenic colonies were selected on PDA containing $150 \mu \mathrm{gmL}^{-1}$ of hygromycin B.

\section{DNA isolation and analysis of $E$. festucae transformants}

DNA was isolated from E. festucae transformants using the methods of Yoder (1988) and Al-Samarrai and Schmid (2000). PCR reaction and cycling conditions were conducted according to manufacturer's instructions (Invitrogen).

\section{Characterisation of $E$. festucae isolates growing in L. perenne}

Epichloë endophytes were artificially inoculated into L. perenne seedlings according to the method of Latch \& Christensen (1985). The phenotype of E. festucae Fl1 $\Delta$ acyA mutants in L. perenne cv. Nui was determined by straining epidermal peels from infected leaf sheath material with $0.15 \%(\mathrm{w} / \mathrm{v})$ aniline blue as described by Christensen et al. (2002).

\section{Transcript Profiling using an $N$. lolii/ L. perenne Affymetrix GeneChip ${ }^{\circledR}$}

A NimbleExpress Affymetrix GeneChip ${ }^{\circledR}$ was developed to compare the transcript profiles of E. festucae F11 $\triangle$ acyA42 with the wild type strain. The majority of the sequences tiled on the microarray originated from EST libraries from N. lolii Lp19 and and L. perenne. Development of the GeneChip ${ }^{\circledR}$ is described in detail in Voisey et al. (2007). L. perenne plants infected with wild type or E. festucae Fl1 $\triangle a c y A 42$ were grown in triplicate in climate controlled conditions, and the pseudostem harvested for extraction of RNA as described (Johnson et al. 2007a). Analysis of RNA quality, labelling, chip hybridisations, washes and GeneChip ${ }^{\circledR}$ scanning followed recommended procedures and were conducted at the Centre for Genomics and Proteomics, School of Biological Sciences, University of Auckland, New Zealand. Microarray data were processed as described in Voisey et al. (2007).

\section{Results and Discussion}

\section{Disruption of the acy $A$ gene in $E$. festucae Fl1}

The acy $A$ gene was deleted in E. festucae Fll as this species is closely related and more amenable to transformation than $N$. lolii. The vector pCRVacyhph was used to insert the hygromycin resistance cassette upstream of the catalytic domain of the acy $A$ gene. Approximately 50 colonies were assessed by PCR for the $h p h$ insertion event. Three colonies with the expected gene replacement, $\triangle a c y A 34, \triangle a c y A 42$ and $\triangle a c y A 47$, were identified and confirmed by Southern analysis (data not presented). Two further colonies, acyA19 and acyA49, with an intact acyA gene plus in ectopic insertion of the gene replacement vector were identified for use as transformation controls.

\section{Phenotypic characterisation of $E$. festucae Fl1 $\triangle$ acy $A$ in culture}

Saprophytic growth of E. festucae F11 $\triangle a c y A$ strains in culture was substantially reduced when compared with the wild type or strains with an ectopic insertion of the hph cassette (data not shown). The growth rate of E. festucae Fl1 $\triangle$ acy $A 42$ could be fully complemented by addition of $7.5 \mathrm{mM}$ cAMP to the media, indicating that CAMP depletion is the cause of the slower growth rate (data not shown). The wild type and ectopic strains (acyA19, acy 449 ) did not change in radial colony diameter in response to cAMP supplementation.

In addition, disruption of acy $A$ substantially increased the production of conidia in culture by E. festucae FL1 when compared with the wild-type or isolates with ectopic integrations of the gene disruption vector. This data suggested that the cAMP signalling pathway negatively regulates production of conidia in E. festucae, which contrasts with other fungi such as Aspergillus fumigatus (Liebmann et al. 2003), A. nidulans (Fillinger et al. 2002) and Magnaporthe grisea (Choi \& Dean 1997), where disruption of adenylate cyclase reduced the number of conidia.

\section{Phenotype of mutant endophyte strains growing in planta}

To evaluate the role of cAMP signalling during infection of plants by epichloë endophytes, mycelia of isolates $\triangle a c y A 34, \triangle a c y A 42$ and $\triangle a c y A 47$ were artificially inoculated into cut seedlings of L. perenne. Both $\triangle a c y A 34$ and $\triangle a c y A 42$ were capable of colonising $L$. perenne, although the success rate (in terms of the number of plants colonised) was much lower than the wild type (data not shown). This suggests that although not essential for infectivity, cAMP may regulate processes that increase the efficacy of the infection process. Conversely, strain $\triangle a c y A 47$ was not infectious. The reason for this has not yet been determined. The visual phenotype of $L$. perenne infected with strains $\triangle a c y A 34$ and $\triangle a c y A 42$ was identical to those infected with wild type $E$. festucae, however the plants were heavily colonised in comparison with plants infected by the wild type strain. Hyphae of $\triangle a c y A 42$ and 34 had a hyper-branching phenotype consistent with continued development of lateral branches after host growth had ceased. Together these data suggest that cAMP signalling is not essential for infectious growth of endophytes in ryegrass, rather is involved in the regulation of hyphal growth in plants. Further work is required to confirm that cAMP levels have been reduced in endophytes as a result of acy $A$ disruption, and that the phenotype of the $\triangle a c y A$ strains can be restored to the wild type by ectopic integration of the wild type acyA gene, thus confirming that the phenotype observed is due to acyA disruption.

\section{Effects of $a c y A$ disruption on expression of plant and endophyte genes during symbiosis}

Large-scale transcript profiling experiments using the $N$. lolii/ $L$. perenne GeneChip ${ }^{\circledR}$ have been conducted to identify genes that are regulated by cAMP during symbiosis (Voisey et al., 2007). We have compared the expression profiles of endophyte and plant genes in pseudostem material infected with wild type $E$. festucae with those of plants infected with the mutant endophyte strain, $\triangle a c y A 42$ (Voisey et al. 2007). The data for each species (endophyte and plant) have been normalised independently using Robust Multi-array Average (RMA , Irizarry et al. 2003) to account for differences in fungal biomass between plants. Data analysis to identify differentially-expressed genes is currently in progress. Preliminary results indicate that many genes were either up or down-regulated in response to disruption of acyA in endophyte-infected plants. In particular a number of endophytic proteases are down-regulated in $\triangle a c y A 42$ in comparison with the wild type association suggesting that proteases are positively regulated by the cAMP signalling network in wild type associations between E. festucae F11 and L. perenne. The majority of differentially-expressed genes in $\triangle a c y A 42$ are of unknown function, and functional annotation of these sequences 
and their role in symbiosis will be a priority for this team in the future.

\section{ACKNOWLEDGEMENTS}

Thanks are due to Catherine Tootill for technical assistance (Grasslands Research Centre, Palmerston North, AgResearch). We would like to acknowledge Liam Williams at the University of Auckland Microarray Facility at the Centre for Genomics and Proteomics (New Zealand) for analysis of RNA quality, labelling of cRNA, and GeneChip ${ }^{\circledR}$ hybridisation and scanning. This research was funded by the New Zealand Foundation for Research Science and Technology (C10X0203) and AgResearch AR\&C project 5598/1

\section{REFERENCES}

Al-Samarrai, T.H.; Schmid, J. 2000. A simple method for extraction of fungal genomic DNA. Letters in Applied Microbiology 30: 53-56.

Brakhage, A.; Liebmann, B. 2005. Aspergillus fumigatus conidial pigment and cAMP signal transduction: significance for virulence. Medical Mycology 43: S75-S82.

Choi, W.; Dean, R.A. 1997. The adenylate cyclase gene MAC1 of Magnaporthe grisea controls appressorium formation and other aspects of growth and development. Plant Cell 9: 1973-1983.

Christensen, M.J.; Bennett, R.J.; Schmid, J. 2002. Growth of Epichloë/Neotyphodium and p-endophytes in leaves of grass hosts. Mycological Research 106: 93-106.

D'Souza, C.A.; Heitman, J. 2001. Conserved cAMP signaling cascades regulate fungal development and virulence. Fems Microbiology Reviews 25: 349-364.

Fillinger, S.; Chaveroche, M.-K.; Shimizu, K.; Keller, N.; d'Enfert, C. 2002. cAMP and ras signalling independently control spore germination in the filamentous fungus Aspergillus nidulans. Molecular Microbiology 44: 1001-1016.

Fleetwood, D.J.; Scott, B.; Lane, A.; Tanaka, A.; Johnson, R.D. 2007. A complex ergovaline gene cluster in Epichloë endophytes of grasses. Applied and Environmental Microbiology: in press.

Irizarry, R.A.; Hobbs, B.; Collin, F.; Beazer-Barclay, Y.D.; Antonellis, K.J.; Scherf, U.; Speed, T.P. 2003. Exploration, normalization, and summaries of high density oligonucleotide array probe level data. Biostatistics 4: 249-264.

Itoh, Y.; Johnson, R.; Scott, B. 1994. Integrative transformation of the mycotoxin-producing fungus, Penicillium paxilli. Current Genetics 25: 508-513.

Johnson, L.J.; Voisey, C.R.; Johnson, R.D.; Khan, A.K.; Park, Z.A.; Ramakrishna, M.; Cao, M.; Simon, D.; Christensen, M.; Bryan, G.T.; Rasmussen, S. 2007a. Dual Affymetrix GeneChip ${ }^{\circledR}$ analysis of the perennial ryegrass-endophyte symbiosis. pp. 509 In: Proceedings of the 6th International Symposium on Fungal Endophytes of Grasses. Eds. Popay, A.J.: Thom, E.R. Grassland Research and Practice Series No.13. New Zealand Grassland Association.
Johnson, R.; Voisey, C.R.; Pratt, J.; Johnson, J.; Bryan, G.T. 2007b. Identification of NRPS gene families from Neotyphodium/ Epichloë endophytic fungi that form mutualistic associations with cool season grasses. pp. 495 In: Proceedings of the 6th International Symposium on Fungal Endophytes of Grasses. Eds. Popay, A.J.: Thom, E.R. Grassland Research and Practice Series No.13. New Zealand Grassland Association.

Klimpel, A.; Gronover, C.S.; Williamson, B.; Stewart, J.A.; Tudzynski, B. 2002. The adenylate cyclase (BAC) in Botrytis cinerea is required for full pathogenicity. Molecular Plant Pathology 3: 439-450.

Latch, G.C.M.; Christensen, M.T. 1985. Artificial infection of grasses with endophytes. Annals of Applied Biology 107: 17-24.

Liebmann, B.; Gattung, S.; Jahn, B.; Brakhage, A.A. 2003. cAMP signaling in Aspergillus fumigatus is involved in the regulation of the virulence gene pksP and in defence against killing by macrophages. Molecular Genetics and Genomics 269: 420-435.

Punt, P.J.; Oliver, R.P.; Dingemanse, M.A.; Pouwels, P.H.; van den Hondel, C.A.M.J.J. 1987. Transformation of Aspergillus based on the hygromycin B resistance marker from Escherichia coli. Gene 56: 117-124.

Rowan, D.D. 1993. Lolitrems, peramine and paxilline: Mycotoxins of the ryegrass/endophyte interaction. Agriculture, Ecosystems and Environment 44: 103-122.

Spiering, M.J.; Lane, G.A.; Christensen, M.J.; Schmid, J. 2005. Distribution of the fungal endophyte Neotyphodium lolii is not a major determinant of the distribution of fungal alkaloids in Lolium perenne plants. Phytochemistry 66: 195-202.

Tan, Y.Y.; Spiering, M.J.; Scott, V.; Lane, G.A.; Christensen, M.J.; Schmid, J. 2001. In planta regulation of extension of an endophytic fungus and maintenance of high metabolic rates in its mycelium in the absence of apical extension. Applied and Environmental Microbiology. 67: 5377-5383.

Voisey, C.R.; Khan, A.K.; Park, Z.A.; Johnson, L.J.; Johnson, R.D.; Ramakrishna, M.; Cao, M.; Bassett, S.; Gaborit, C.N.; McCulloch, A.F.; Simon, D.; Rasmussen, S.; Christensen, M.T.; Bryan, G.T. 2007. Development of an Affymetrix dual species (Neotyphodium lolii/ Lolium perenne) Symbiosis GeneChip®.pp. 505 In: Proceedings of the 6th International Symposium on Fungal Endophytes of Grasses. Eds. Popay, A.J.: Thom, E.R. Grassland Research and Practice Series No.13. New Zealand Grassland Association.

Vollmer, S.J.; Yanofsky, C. 1986. Efficient Cloning of Genes of Neurospora crassa. Proceedings of the National Academy of Sciences, USA 83: 4869-4873.

Yoder, O.C. 1988. Cochliobolus heterostrophus, cause of southern corn leaf blight. Advances in Plant Pathology 6: 93-112.

Young, C.; Itoh, Y.; Johnson, R.; Garthwaite, I.; Miles, C.; Munday-Finch, S.; Scott, B. 1998. Paxilline-negative mutants of Penicillium paxilli generated by heterologous and homologous plasmid integration. Current Genetics 33: 368-377. 